Supercapattery: Merit-merge of capacitive and Nernstian charge storage mechanisms

George Zheng Chen

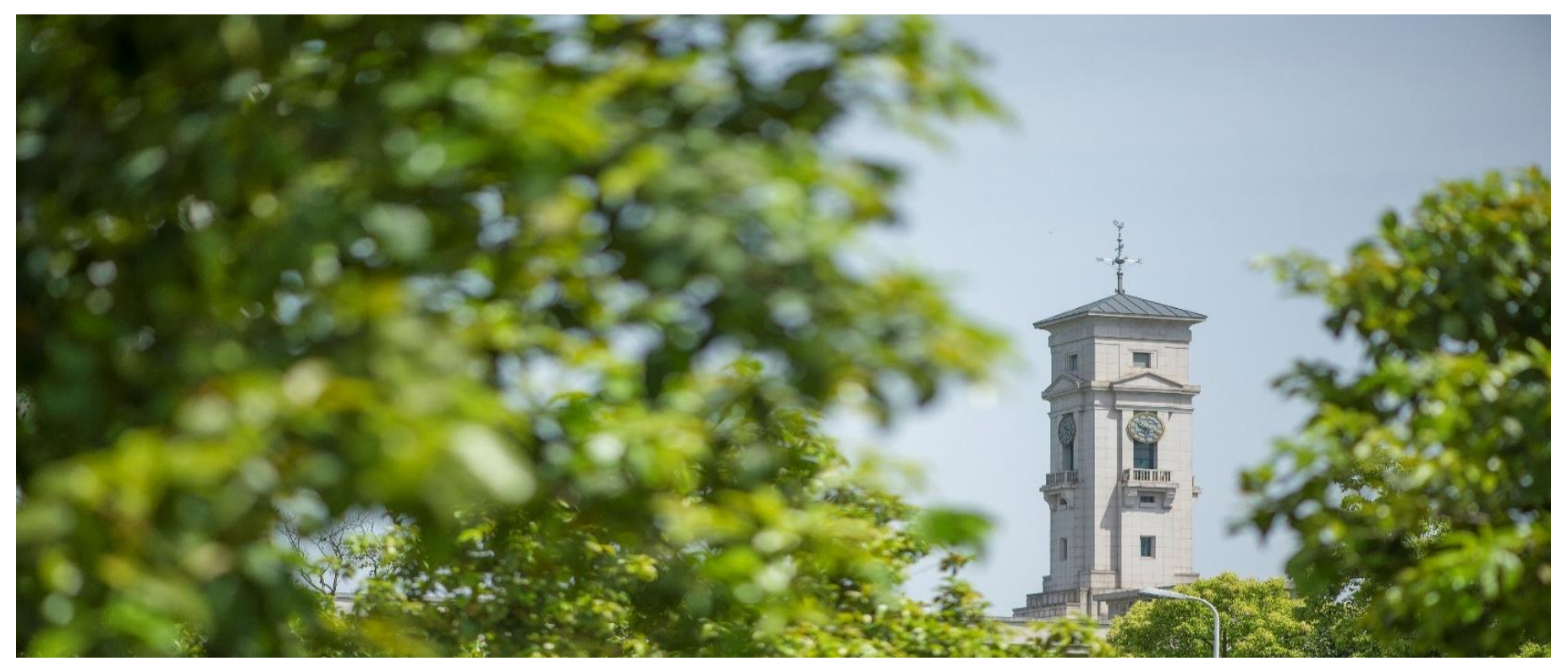


University of Nottingham Ningbo China, 199 Taikang East Road, Ningbo, 315100, Zhejiang, China.

First published 2020

This work is made available under the terms of the Creative Commons Attribution 4.0 International License:

http://creativecommons.org/licenses/by/4.0

The work is licenced to the University of Nottingham Ningbo China under the Global University Publication Licence:

https://www.nottingham.edu.cn/en/library/documents/researchsupport/global-university-publications-licence-2.0.pdf 


\title{
Supercapattery: Merit-merge of capacitive and Nernstian charge storage mechanisms
}

\author{
George Zheng Chen ${ }^{1,2}$
}

${ }^{1}$ Department of Chemical and Environmental Engineering, Faculty of Engineering, University of Nottingham, University Park, Nottingham NG7 2RD, UK

${ }^{2}$ Department of Chemical and Environmental Engineering, Faculty of Science and

Engineering, University of Nottingham Ningbo China, University Park, Ningbo 315100, China

Email: george.chen@nottingham.ac.uk

\begin{abstract}
Supercapattery is the generic name for hybrids of supercapacitor and rechargeable battery. Batteries store charge via Faradaic processes, involving reversible transfer of localised or zone-delocalised valence electrons. The former is governed by the Nernst equation. The latter leads to pseudocapacitance (or Faradaic capacitance) which may be differentiated from electric double layer capacitance with spectroscopic assistance such as electron spin resonance. Since capacitive storage is the basis of supercapacitors, the combination of capacitive and Nernstian mechanisms has dominated supercapattery research since 2018, covering nanostructured and compounded metal oxides and sulfides, water-in-salt and redox active electrolytes and bipolar stacks of multi-cells. The technical achievements so far, such as specific energy of $270 \mathrm{Wh} / \mathrm{kg}$ in aqueous electrolyte, and charging-discharging for over 5000 cycles, benchmark a challenging but promising future of supercapattery.
\end{abstract}

Keywords

Supercapattery, Nernstian storage, delocalised valence electrons, pseudocapacitance, bipolar electrode, water-in-salt electrolytes, redox active electrolytes

\section{Challenges to conventional electrochemical energy storage}

Replacing fossil fuels by renewables requires energy storage, for which electrochemical energy storage (EES) devices are a desirable fit because of their modular nature, commercial choices and potentially fossil-comparable energy capacity. On the last point, oxidation of lithium in electrochemical cells causes a Gibbs energy change $\left(\Delta \mathrm{G}^{\circ}{ }_{\mathrm{Li}}=8.56 \mathrm{kWh} / \mathrm{kg}\right.$ at 1000 $\left.{ }^{\circ} \mathrm{C}\right)$ that is comparable to that of coal combustion $(9.16 \mathrm{kWh} / \mathrm{kg})$ in internal combust engines (ICEs) [1]. Representative commercial EES devices include rechargeable batteries (RBs) and supercapacitors (SCs), whilst flow batteries are suitable for stationary and large scale storage [2-4]. Although far better in energy efficiency than ICEs (ca. 20\%), EES devices have neither performed to expectations. Laboratory-tested lithium-air battery (LAB) and commercial lithium-ion battery (LIB) can only store energy up to 1.0 and $0.3 \mathrm{kWh} / \mathrm{kg}$, respectively, pending further improvement in rate and durability.

Performance wise, RBs offer higher storage capacity than SCs which are however better in power capability, energy efficiency, and cycle life. These complementary merits have encouraged development of several hybrid devices, including lithium-ion capacitors, redox 
capacitors, and pseudocapacitors [5]. These hybrids store charge differently from a capacitor, but the word capacitor in these names has led to misuse of capacitance as a performance indicator [6]. For unambiguous classification and comparison, the generic name supercapattery (= supercapacitor + battery) was proposed in 2007 , followed by laboratory demonstration later $[7,8]$. In fact, combination of capacitive and lithium storage electrodes was reported in earlier literatures, although the term "lithium-ion capacitor" (LIC) first appeared also in 2007 [9-12]. Because of their close relation with LIBs, research and development of LICs have progressed fast, along with other ion capacitors [13-15]. On the contrary, supercapattery rarely appeared in the literature before 2015. The recent growing interests are partly driven by curiosity and exploration of new and improved EES mechanisms, materials and devices beyond SCs and RBs [16-18]. The other and more fundamental reason is related to pseudocapacitance that has been, unfortunately, misused to account for the behaviour of many new transition metal compounds that are capable of Nernstian storage.

\section{Pseudocapacitance explained}

All rechargeable EES devices work following one or a combination of electric double layer (EDL) capacitive, pseudocapacitive and battery-like mechanisms [4]. EDL storage is physical at the electrode/electrolyte interface, whilst the latter two involve charge transfer reactions on electrode and hence are both Faradaic in nature. Battery-like or Nernstian storage is widely known to result from reversible electrode reactions that are broadly governed by the Nernst equation. It is featured by peak-shaped cyclic voltammograms (CVs) and by potential plateaux on galvanostatic charging-discharging plots (GCDs). Pseudocapacitance (or Faradaic capacitance) presents features same as those of EDL capacitance, namely rectangular CVs and linear GCDs. A hypothesis explains such differences by the transfer of localised and partially or zone-delocalised valence electrons, leading to Nernstian and pseudocapacitive responses, respectively [19]. It agrees with density functional theory modelling of oxygen doped graphenes [20,21]. According to the band model [22], localised valence electrons have a fixed electronic energy level, corresponding to a fixed potential for their transfer. This in turn leads to peak-shaped CVs, and plateau-featured GCDs for Nernstian storage. For zone-delocalised valence electrons as in semiconductors (instead of full delocalisation as in metals and perfect monolayer graphene), their very close electronic energy levels are merged to a sufficiently wide band, into or from which electron transfer occurs in a continuous range of potentials. This hypothesis reflects well the rectangular CVs and linear GCDs for pseudocapacitive storage.

Although electrochemical characteristics of pseudocapacitance and EDL capacitance are recognised to be the same $[4,6,23-25]$, some authors claimed differentiation between the two based on simulation against equation (11) or (12) below [26-28],

$$
\begin{aligned}
& i=\mathrm{a} v+\mathrm{b} v^{1 / 2} \\
& i=\mathrm{m} v^{\mathrm{n}}
\end{aligned}
$$

where $i$ and $v$ are the current and potential scan rate of the CV, respectively, and $a, b, m$ and $\mathrm{n}$ are constants. For surface confined processes, $\mathrm{b}=0, \mathrm{n}=1$, but under diffusion control, $\mathrm{a}=$ $0, n=1 / 2$. Otherwise, the electrode reaction is under mixed control. It was assumed, but incorrectly, that the EDL currents resulted from surface confined changes and hence were 
proportional to $v$, whilst Faradaic contributions were diffusion controlled, showing a linearity of $i$ on $v^{1 / 2}$. Obviously, these assumptions contradict the basic knowledge that surface confined processes, either capacitive or Nernstian, dominate the behaviour of relatively thin electrode coatings. Also, diffusion control could happen in relatively thick electrode coatings, into or from which transport of ions are necessary to maintain charge neutrality, for both capacitive and Nernstian processes.

In fact, a Faradic process, either Nernstian or capacitive, always unpairs or pairs electrons in the atomic or molecular orbits, which in turn generates or demolishes spins that can be monitored by electron spin resonance (ESR) spectroscopy [29,30]. Fig. 1a shows the CVs of polyaniline (PAn). Whilst the three peak couples (A1/C1, A2/C2 and $A 3 / C 3$ ) are well explained elsewhere [33,34], the capacitive responses are evident between 0.1 and $0.5 \mathrm{~V}$. For comparison, Fig. $1 \mathrm{~b}$ presents a typical cyclic esrogram of PAn between -0.2 and $0.5 \mathrm{~V}$ [30]. It can be seen that the ESR signal varied similarly as the currents on the CVs between 0.1 and $0.5 \mathrm{~V}$, which is strong evidence of Faradaic dis-/charging with insignificant EDL contribution, if any. Note that $\mathrm{A} 1$ on the esrogram is at a more positive potential than $\mathrm{A} 1$ on the CVs. This difference is due to the ESR signal being proportional to the amount of charge passed, instead of the charge flow rate, i.e. the current.

Ironically, pseudocapacitance is responsible for the synthesis and test of a large number of nanostructured transition metal compounds, specially nickel and cobalt based oxides. These materials typically showed Nernstian features with appreciable power capability and cycling durability, but were unfortunately interpreted by pseudocapacitance with misleadingly high capacitance values [31,32]. Following several criticisms [4-6, 24,35], such Nernstian materials have been coupled with EDL materials in supercapatteries [36-45].

\section{Basics of supercapattery and early development}

Aiming at merging the merits of $\mathrm{SC}$ and $\mathrm{RB}[4,5,18,24]$, supercapattery engages with both capacitive and Faradaic mechanisms $[18,46]$. Because capacitive storage can be EDL or pseudocapacitive, and Faradaic storage can be pseudocapacitive or Nernstian, there is a large number of combination options.

Supercapattery behaviour can result from materials, such as heat treated nickel hydroxide films which exhibited fairly rectangular CVs from 0 to $0.35 \mathrm{~V}$ vs. SCE, but presented large current peaks at more positive potentials in aqueous $\mathrm{KOH}$ [47]. Composites of manganese oxides $\left(\mathrm{MnO}_{\mathrm{x}}, 1.5<\mathrm{x} \leq 2\right)$ with carbon nanotubes (CNTs) or graphenes can also store charges in mixed mechanisms [48-50]. Further, engaging electron transfer reactions of soluble species, such as iodide ions, with EDL capacitance of a porous carbon electrode is another effective way to combine capacitive and Nernstian mechanisms [24,52-54].

The device approach to supercapattery considers the relations between the two electrodes. Firstly, the charges passing through the capacitive $\left(Q_{c a p}\right)$ and Nernstian $\left(Q_{b a t}\right)$ electrodes must be equal as expressed by equation (13) [4] where $Q_{s p}$ is the specific charge, and $C_{s p}$ the specific capacitance.

$Q_{b a t}=m_{b a t} Q_{s p}=m_{c a p} C_{s p} \Delta E_{c a p}=Q_{c a p}$

$\Delta E_{c a p}=\frac{Q_{s p} m_{\text {bat }}}{C_{s p} m_{c a p}}$ 
Equation (14) is useful for designing supercapattery, disregarding whether the capacitive or Nernstian electrode is the positrode or negatrode.

Secondly, equal currents occur on both electrodes at any time. For reversible storage in thin films, equation (15) governs the relation, linking with the Nernst equation (16) for reduction (charging on positrode, or discharging on negatrode) [4]:

$i_{c a p}=m_{c a p} C_{s p} \frac{d E_{c a p}}{d t}=\frac{n F \Gamma_{\text {redox }}}{t}=i_{\text {bat }}$

$E_{\text {bat }}=E_{\text {bat }}^{o}+\frac{R T}{n F} \ln \left(\frac{1-x}{x}\right), \quad x=\frac{\Gamma_{\text {redox }}}{\Gamma_{\text {total }}}=\frac{i t}{n F \Gamma_{\text {total }}}$

where $\Gamma$ is the amount of the relevant or all redox species in the thin film. Equations (15) and (16) were used to calculate the GCD plots in Fig. 2a to 2c [4]. In practical cases, charging capacitive electrodes, either EDL or Faradaic, is highly reversible and hence fast. Thus, in the calculations, the charging rates of the cell are assumed to be such that the Nernstian electrode could respond in accordance with the Nernst equation (16). These are indeed achievable as shown by the experimentally recorded GCDs in Fig. $2 d$ to $2 f[38,55,56]$.

\section{Selected progresses between 2018 and 2019}

\subsection{Electrode materials}

Since 2018, supercapattery research, excluding ion capacitors which are reviewed elsewhere [13-15], has focused on novel nanostructured and compounded Nernstian materials [16,17,37-45]. For example, hydrothermal doping $40 \%$ sulfur into $\mathrm{FeCO}_{2} \mathrm{O}_{4}$ produced nanocaterpillars, and increased the capacitance to $1801 \mathrm{~F} / \mathrm{g}$ from $779 \mathrm{~F} / \mathrm{g}$ without doping at $2 \mathrm{~A} / \mathrm{g}$. The $\mathrm{CVs}$ and GCDs were fairly capacitive, but the capacitive potentials ranged only from 0 to $0.5 \mathrm{~V}$ vs. $\mathrm{Ag} / \mathrm{AgCl}$. Supercapatteries made from an undoped $\mathrm{FeCO}_{2} \mathrm{O}_{4}$ negatrode and the sulfur-doped positrode performed very well in aqueous $3 \mathrm{~mol} / \mathrm{L} \mathrm{KOH}$. The cell voltage was $1.45 \mathrm{~V}$, achieving specific energy and power of $140 \mathrm{Wh} / \mathrm{kg}$ and $1434 \mathrm{~W} / \mathrm{kg}$, respectively, and over 5000 dis-/charging cycles [16]. However, CVs and GCDs of the supercapattery showed clear resistive distortion, indicating higher resistance of the undoped negatrode. Also, energy efficiency estimated from the GCD at $2 \mathrm{~A} / \mathrm{g}$ was lower than $60 \%$.

Nanosheets of $\mathrm{MoS}_{2}$ were hydrothermally grown in the pores of a carbon nitride template [17]. In aqueous $1 \mathrm{~mol} / \mathrm{L} \mathrm{KOH}$, the composite showed Nernstian CVs and GCDs from $0.0 \mathrm{~V}$ to $0.5 \mathrm{~V}$. The specific charge capacity reached over $500 \mathrm{C} / \mathrm{g}$. Surprisingly, a symmetrical supercapattery was built from this material, leading to unreasonable tests and results.

An interesting Nernstian positrode was made from nanosheets of carbon-coated $\mathrm{Li}_{3} \mathrm{~V}_{2}\left(\mathrm{PO}_{4}\right)_{3}$ [45]. $\mathrm{Li}_{3} \mathrm{~V}_{2}\left(\mathrm{PO}_{4}\right)_{3}$ offers three valence states of $\mathrm{V}$ (III, IV and $\mathrm{V}$ ), corresponding to storage of three $\mathrm{Li}^{+}$ions per formula at high positive potentials, $>3.8 \mathrm{~V}$ vs Li/Li+. With an activated carbon negatrode in mixed organic carbonates, the supercapattery was tested to $2.7 \mathrm{~V}$ to ensure reversible lithium storage in $\mathrm{Li}_{3} \mathrm{~V}_{2}\left(\mathrm{PO}_{4}\right)_{3} / \mathrm{C}$. The cell GCDs presented two shoulders, reflecting two steps of lithium storage. Reported specific energy and power were $53 \mathrm{Wh} / \mathrm{kg}$ and $3 \mathrm{~kW} / \mathrm{kg}$, respectively. However, after 2000 cycles, capacity loss reached 35\%, apparently because repeated lithium-ion insertion and removal caused microscopic fatigue damage in the positrode. 
Carbon negatrodes are often chosen for aqueous electrolytes, imposing high overpotentials for hydrogen evolution. Further, nano-pores of activated carbon permit proton or water reduction to adsorbed hydrogen atoms or molecules, but restrict their nucleation and growth into bubbles. These adsorbed hydrogen species can also be re-oxidised and hence increase charge storage capacity $[57,58]$.

More desirable negatrodes are based on active metals because of their very negative redox potentials and reversible electrode reactions $[13-15,55,56]$. The concern on dendritic deposition upon cycling are addressed by several approaches, such as pulsed charging for both zinc and lithium deposition $[59,60]$ and using 3D structured (porous) current collectors (e.g. copper foam) for lithium deposition [61,62].

Transition metal oxides are usually used on positrode, but iron or tungsten oxide undergoes reversible changes at negative potentials [63-65]. The crystalline/amorphous core/shell structured iron oxide with oxygen vacancies exhibited both capacitive and Nernstian features in $1 \mathrm{~mol} / \mathrm{L} \mathrm{LiOH}$ as shown in Fig. 3a and 3b. Specific capacitance of $701 \mathrm{~F} / \mathrm{g}$ was claimed as averaged from the GCD plot. However, the reported GCD at $0.5 \mathrm{~mA} / \mathrm{cm}^{2}$ was nonlinear, whilst the equation used for capacitance calculation, $C_{S}=\frac{I \Delta t}{m \Delta E}$, actually gives results for the inserted triangular dashed line in Fig. 3b. Thus, the performance should be better represented by specific charge. Further, the GCD is asymmetrical along the time axis, showing longer times for charging than discharging, suggesting a Columbic efficiency much lower than that for a true capacitive electrode.

Fig. $3 \mathrm{c}$ and $3 \mathrm{~d}$ compare the $\mathrm{CVs}$ and $\mathrm{GCDs}$ of $\mathrm{WO}_{3}$ and $\mathrm{W}_{5} \mathrm{O}_{14}$. Clearly, the oxygen deficient $\mathrm{W}_{5} \mathrm{O}_{14}$ performed better. In addition, the crystalline $\mathrm{W}_{5} \mathrm{O}_{14}$ contained more ion channels than $\mathrm{WO}_{3}$. Consequently, the specific capacitance increased from $371 \mathrm{~F} / \mathrm{g}$ for $\mathrm{WO}_{3}$ to $524 \mathrm{~F} / \mathrm{g}$ for $\mathrm{W}_{5} \mathrm{O}_{14}$ as derived from fairly linear GCDs. Note that, against convention, the GCDs in Fig. $3 \mathrm{~d}$ start from discharging and then charging.

\subsection{Electrolytes}

Aqueous electrolytes match well with many redox materials [16-18, 37-44], and support cells to work at high voltages (>12.4 V) without water decomposition. For example, lead-acid batteries use sulfuric acid as electrolyte and work at $>2.0 \mathrm{~V}$.

An advanced approach to avoiding water decomposition is to use the so called water in salt (WIS) electrolytes in which all water molecules are bounded to, or surrounded closely by salt ions, water decomposition may not occur up to $3.0 \mathrm{~V}$ [66-69]. However, because of the minimum separation by a few layers of coordination and solvation water molecules, and hence strong attractions between cations and anions, WIS electrolytes show high viscosity and low conductivity. Addition of co-solvents could improve the performance, but also narrow the potential window $[67,70]$.

Non-aqueous electrolytes, including ionic liquids, offer wider potential windows for utilising the very negative potentials of, for instance, lithium metal or lithiated carbon [9-11,13$15,45,71-73]$. In such cases, the electrolyte not only conduct ions, but also participate in redox reaction, e.g. lithium-ion reduction or intercalation, which contributes directly to dis/charging of the cell. 
Similarly, redox electrolytes also help enhance storage in supercapacitors via both capacitive and Nernstian mechanisms [51-54,74]. Comparing with making new electrode materials, dissolved redox species (DRS) in electrolyte offer a simpler and cheaper approach to enhanced storage. A key issue is the cycling of electro-reacted DRS between the positrode and negatrode via diffusion. For example, halide ions $\left(X^{-}\right)$are the early DRS $[51,74]$ with a reversible electro-reaction of $3 X^{-}=X_{3}^{-}+2 e$. Because both $X^{-}$and $X_{3}{ }^{-}$are anions, they should be electrostatically attracted to, and trapped inside the pores of the activated carbon positrode. However, oxidation of $\mathrm{I}^{-}$occurs near the equal potential of the positrode and negatrode at full discharge, causing insufficient electrostatic attraction and hence redox cycling [52]. This understanding explains the current peaks near $0 \mathrm{~V}$ on the cell CV in Fig. 4a, and agrees with the absence of any current peaks on the CVs in Fig. $4 \mathrm{~b}$ for the cell containing $\mathrm{Br}^{-}$whose oxidation potential is about $500 \mathrm{mV}$ more positive than that of $\mathrm{I}^{-}$. Fig. 4c shows that simply discharging the cell to $0.1 \mathrm{~V}$ (not $0 \mathrm{~V}$ ) also eliminated redox cycling [53]. By doing so, the cell repeated dis-/charging at $0.5 \mathrm{~A} / \mathrm{g}$ to 4000 cycles with only $4 \%$ capacitance loss.

\subsection{Emerging merit-merging innovations}

A particular recent progress is the combination of more than two storage mechanisms into supercapattery. A zinc-bromine supercapattery was studied, combining EDL capacitive, pseudocapacitive and Nernstian storage [54], although the claimed pseudocapacitive storage was in fact Nernstian with $\mathrm{Br}^{-}$oxidation. This supercapattery was tested to 270 $\mathrm{Wh} / \mathrm{kg}$ at $9300 \mathrm{~W} / \mathrm{kg}$ with $81 \%$ capacity retention after 5000 cycles.

The combination of a positrode of the polyaniline/nano carbon fibres (NCF) composite, a NCF negatrode for lithium intercalation, and a polymer gel electrolyte had led to a flexible supercapattery that offered specific energy of $106.5 \mathrm{Wh} / \mathrm{kg}$, and $70.3 \%$ capacity retention after 9000 cycles [75].

Last but not the least, the sandwich configuration of supercapattery (and supercapacitor) permits to use bipolar electrodes to serially stack multi-cells [76]. A basic advantage is that if $n$ cells are to be serially connected, the number of electrodes is $2 n$ for external connection, but $n+1$ for bipolar stacking [76]. This will reduce significantly the mass and volume of the stack, and benefit to all gravimetric and volumetric properties. Importantly, the bipolar plates must be both liquid and gas proof. While the initial effort used titanium foils as the bipolar plates, it was shown that $50 \mu \mathrm{m}$ thick carbon black/polyethylene composite films could be sufficiently conductive (through the film plane) and non-permeable, which also helped the fabrication of pouch cells for stacking [77]. The stack of bipolarly connected Zn$\mathrm{Br}_{2}$ cells performed satisfactorily, reaching $50 \mathrm{Wh} / \mathrm{L}$ and $500 \mathrm{~W} / \mathrm{L}$ with less than $1 \%$ loss over 500 dis-/charging cycles. Graphite plates with vertically grown CNTs on both sides were also used to stack EDL cells that retained $96.7 \%$ of the initial capacity after 50000 cycles [78].

\section{End remarks}


Supercapattery is being developed amongst questions on what should be defined for battery and supercapacitor, particularly in relation with the confusion on pseudocapacitance. It is identified that electrode reactions can involve the transfer of either localised valence electrons governed by the Nernst equation which is the basis of batteries, or zonedelocalised valence electrons leading to pseudocapacitive behaviour. Aiming at merging the merits of Faradaic Nernstian and capacitive storage mechanisms, supercapattery research has progressed steadily since 2018 , utilising nanostructured and compounded metal oxides and sulfides capable of Nernstian storage, salt-in-water and redox active electrolytes, and bipolar stacks. There are undoubtedly further improvements but, thanks to the knowledge and technology advancements in batteries and supercapacitors, supercapattery will become more competitive and promising in the near future.

\section{Conflict of interest statement}

The author has no conflict of interest to declare.

\section{Acknowledgements}

The author thanks the invaluable research contributions from all collaborators, and postdoctoral and postgraduate co-workers whose names appear in the list of References, and also the financial supports from the EPSRC (EP/J000582/1, GR/R68078), Royal Society (Braine Mercer Feasibility Award, 2006), E.ON AG (Energy Storage 2007), Season Long Cleantech Ltd (Beijing), and Ningbo Municipal People's Governments (3315 Plan and 2014A35001-1). Responsibility for the content of this publication lies with the author.

\section{References}

[1] Outotec: HSC Chemistry 72012.

[2]** Gür TM: Review of electrical energy storage technologies, materials and systems: challenges and prospects for large-scale grid storage, Energy Environ Sci 2018, 11:26962767. https://doi.org/10.1039/C8EE01419A

This review article is a useful reference for energy storage research, highlighting EES in the context of all currently available and predictable major energy storage technologies. Particularly, very useful 15 data tables and 60 illustrative figures and data plots are provided for easy understanding, comparison and analysis.

[3] Owen J: Powering the next generation. Chem Ind 2001, 18:572-576.

[4] Chen GZ: Supercapacitor and supercapattery as emerging electrochemical energy stores. Int Mater Rev 2017, 62:173-202. https://doi.org/10.1080/09506608.2016.1240914

[5]* Akinwolemiwa B, Chen GZ: Fundamental consideration for electrochemical engineering of supercapattery. J Brazilian Chem Soc 2018, 29:960-972.

http://dx.doi.org/10.21577/0103-5053.20180010 
The authors have made a good effort to clarify some typical misuses of scientific and technical terms, and conceptual misunderstanding and confusions in the EES literature, such as anode and cathode versus negatrode and positrode in terms of electrode reactions and electrical polarity, and pseudocapacitance and battery-like storage in terms of Faradaic processes.

[6] Xie J, Yang PP, Wang Y, Qi T, Lei Y, Li CM: Puzzles and confusions in supercapacitor and battery: Theory and solutions. J Power Sources 2018, 401:213-223.

https://doi.org/10.1016/j.jpowsour.2018.08.090

[7] Company Profile: E.ON funds storage technologies. Renewable Energy Focus 2008, 9:10. https://doi.org/10.1016/S1471-0846(08)70108-2.

[8] Hu D, Peng C, Chen GZ: Electro-deposition of non-conducting polymers: Roles of carbon nanotubes in the process and products. ACS Nano 2010, 4:4274-4282.

https://doi.org/10.1021/nn100849d

[9] Amatucci GG, Badway F, Du Pasquier A, Zheng T: An asymmetric hybrid nonaqueous energy storage cell. J Electrochem Soc 2001, 148:A930-939.

https://doi.org/10.1149/1.1383553

[10] Aida T, Yamada K, Morita M: An advanced hybrid electrochemical capacitor that uses a wide potential range at the positive electrode. Electrochem Solid State Lett 2006, 9:A534A536. https://doi.org/10.1149/1.2349495

[11] Woo SW, Dokko K, Nakano H, Kanamura K: Bimodal porous carbon as a negative electrode material for lithium-ion capacitors. Electrochem 2007, 75:635-640.

https://doi.org/10.5796/electrochemistry.75.635

[12] Web of Science. https://wok.mimas.ac.uk, accessed on 04 February 2020.

[13]** Ding J, Hu WB, Paek E, Mitlin D: Review of hybrid ion capacitors: From aqueous to lithium to sodium. Chem Rev 2018, 118:6457-6498.

https://doi.org/10.1021/acs.chemrev.8b00116

This is a good review article on lithium ion and other ion capacitors, highlighting the motivation and principle of hybridisation of rechargeable battery with supercapacitor. Note that anode and cathode used in this literature are replaced by negatrode and positrode in this article.

[14]* Chen JT, Yang BJ, Liu B, Lang JW, Yan XB: Recent advances in anode materials for sodium- and potassium-ion hybrid capacitors. Curr Opin Electrochem 2019, 18:1-8. https://doi.org/10.1016/j.coelec.2019.07.003

This article reviews a relatively rare collection of literatures on sodium and potassium ion capacitors, focusing on the anode (= negatrode) materials. This article is worth reading if one considers the sustainability of energy storage technologies in terms of the wide and cheap availability of sodium and potassium resources compared with the highly geographically limited lithium resources.

[15]* Zou KY, Cai P, Cao XY, Zou GQ, Hou HS, Ji XB: Carbon materials for high-performance lithium ion capacitor. Curr Opin Electrochem 2020, 21:31-39.

https://doi.org/10.1016/i.coelec.2020.01.005. 
In the context of LICs, the authors have focused on the preparation, characterisation and application of various carbon materials for making the cathode (= positrode) and anode (= negatrode), highlighting the ways for, and effects of nanoengineering, doping, graphitisation, porous structuring and surface modification.

[16]* Lalwani S, Joshi A, Singh G, Sharma RK: Sulphur doped iron cobalt oxide nanocaterpillars: An electrode for supercapattery with ultrahigh energy density and oxygen evolution reaction, Electrochim. Acta 2019, 328: 135076.

https://doi.org/10.1016/j.electacta.2019.135076

The authors report a novel study on the positive contribution of doping $\mathrm{Fe}_{2} \mathrm{CoO}_{4}$ with sulfur to increasing the specific capacitance. The hydrothermal process for sulfur doping is likely also effective on other transition metal oxides.

[17]* Joseph N, Bose AC: Metallic $\operatorname{MoS}_{2}$ grown on porous $\mathbf{g}-\mathrm{C}_{3} \mathrm{~N}_{4}$ as an efficient electrode material for supercapattery application. Electrochim Acta 2019, 301:401-410. (Symmetric cell) https://doi.org/10.1016/j.electacta.2019.01.155

The authors report a hydrothermal process for growing redox active $\mathrm{MoS}_{2}$ in the sub-micron pores of a $\mathrm{C}_{3} \mathrm{~N}_{4}$ template. The idea to prepare a composite of two metallic compounds via direct growth one in the porous template of another is novel and effective. While CVs and GCDs the composite show good Nernstian storage performance, it is advisable for readers not to test Nernstian materials in a symmetrical cell.

[18] Yu LP, Chen GZ: Supercapatteries as high-performance electrochemical energy stores. Electrochem Energy Rev 2020, 3: 271-285. https://doi.org/10.1007/s41918-020-00063-6

[19] Zhang SW, Chen GZ: Manganese oxide based materials for supercapacitors. Energy Mater: Mater Sci Eng Energy Sys 2008, 3:186-200.

https://doi:org/10.1179/174892409X427940

[20] Li JF, O'Shea J, Hou XH, Chen GZ: Faradaic processes beyond Nernst's law: Density functional theory assisted modelling of partial electron delocalisation and pseudocapacitance in graphene oxides. Chem Commun 2017, 53:10414-10417. https://doi.org/10.1039/c7cc04344a

[21]* Song C, Wang JY, Meng ZL, Hu FY, Jian XG: Density functional theory calculations of the quantum capacitance of graphene oxide as a supercapacitor electrode. ChemPhysChem 2018, 19:1579-1583. https://doi.org/10.1002/cphc.201800070

The authors report the outcomes from DFT modelling of several types of oxygen doped graphene, confirming the finding and prediction of Ref. 20 in terms of capacitance enhancement resulting from oxygen doping.

[22] Bard AJ, Faulkner LR: Electrochemical Methods: Fundamentals and Applications. Wiley, New York, 2001.

[23] Conway BE: Transition from supercapacitor to battery behavior in electrochemical energy-storage. J Electrochem Soc 1991, 138:1539-1548. https://doi.org/10.1149/1.2085829

[24] Akinwolemiwa B, Peng C, Chen GZ: Redox electrolytes in supercapacitors. J

Electrochem Soc 2015, 162:A5054-A5059. https://doi.org/10.1149/2.0111505jes 
[25] Jiang YQ, Liu JP: Definitions of pseudocapacitive materials: A brief review. Energy Environ Mater 2019, 2:30-37. https://doi.org/10.1002/eem2.12028

[26] Wang J, Polleux J, Lim J, Dunn B: Pseudocapacitive contributions to electrochemical energy storage in $\mathrm{TiO}_{2}$ (anatase) nanoparticles. J Phys Chem C 2007, 11:14925-14931. https://doi.org/10.1021/ip074464w

[27] Yu F, Liu ZC, Zhou RW, Tan DM, Wang HX, Wang FX: Pseudocapacitance contribution in boron-doped graphite sheets for anion storage enables high-performance sodium-ion capacitors. Mater Horiz 2018, 5:529-535. https://doi.org/10.1039/C8MH00156A

[28] Son Y, Ma J, Kim N, Lee T, Lee Y, Sung J, Choi S-H, Nam G, Cho H, Yoo Y, Cho J: Quantification of Pseudocapacitive Contribution in Nanocage-Shaped Silicon-Carbon Composite Anode. Adv Energy Mater 2019, 9:1803480.

https://doi.org/10.1002/aenm.201803480

[29] Waller AM, Compton RG: Simultaneous alternating-current impedance electron-spin resonance study of electrochemical doping in polypyrrole. J Chem Soc-Farad Trans 1989, 85:977-990. https://doi.org/10.1039/f19898500977

[30] Albery WJ, Chen, Z, Horrocks BR, Mount AR, Wilson PJ, Bloor, D, Monkman AT, Elliott CM: Spectroscopic and electrochemical studies of charge-transfer in modified electrodes. Farad Discuss 1989, 88:247-259. https://doi.org/10.1039/dc9898800247

[31] Wang HL, Casalongue HS, Liang YY, Dai HJ: $\mathrm{Ni}(\mathrm{OH})_{2}$ nanoplates grown on graphene as advanced electrochemical pseudocapacitor materials. J Am Chem Soc 2010, 132:7472-7477. https://doi.org/10.1021/ja102267j

[32] Xiao Y, Wei W, Zhang MJ, Jiao S, Shi YC, Ding SJ: Facile surface properties engineering of high-quality graphene: toward advanced Ni-MOF heterostructures for high-performance supercapacitor electrode. ACS Appl Energy Mater 2019, 2:2169-2177.

https://doi.org/10.1021/acsaem.8b02201

[33] Peng C, Zhang SW, Zhou XH, Chen GZ: Unequalisation of electrode capacitances for enhanced energy capacity in asymmetrical supercapacitors. Energy Environ Sci 2010, 3:1499 - 1502. http://dx.doi.org/10.1039/c0EE00228c

[34] Peng C, Hu D, Chen GZ: Theoretical specific capacitance based on charge storage mechanisms of conducting polymers: Comment on 'Vertically oriented arrays of polyaniline nanorods and their super electrochemical properties'. Chem Commun 2011, 47:4105-4107. http://dx.doi.org/10.1039/c1cc10675a

[35] Brousse T, Belanger D, Long JW: To be or not to be pseudocapacitive? J Electrochem Soc 2015, 162:A5185-A5189. https://doi.org/0.1149/2.0201505jes

[36] Shao H, Padmanathan N, McNulty D, O'Dwyer C, Razeeb KM: Supercapattery based on binder-free $\mathrm{CO}_{3}\left(\mathrm{PO}_{4}\right)_{2} \cdot \mathbf{8} \mathrm{H}_{2} \mathrm{O}$ multilayer nano/microflakes on nickel foam. ACS Appl Mater Interfaces 2016, 8:28592-28598. https://doi.org/10.1021/acsami.6b08354

[37] Surendran S, Shanmugapriya S, Sivanantham A, Shanmugam S, Selvan RK: Electrospun carbon nanofibers encapsulated with NiCoP: A multifunctional electrode for supercapattery and oxygen reduction, oxygen evolution, and hydrogen evolution reactions. Adv. Energy Mater 2018, 8:1800555. https://doi.org/10.1002/aenm.201800555 
[38]* Lin JH, Zhong ZX, Wang HH, Zheng XH, Wang YH, Qi JL, Cao J, Fei WD, Huang YD, Feng JC: Rational constructing free-standing Se doped nickel-cobalt sulfides nanotubes as battery-type electrode for high-performance supercapattery. J Power Sources 2018, 407:613. https://doi.org/10.1016/j.jpowsour.2018.10.046

The authors report a rare work on doping Se into $\mathrm{Ni}$-Co sulfide in the form of nanotubes or nanofibrils grown vertically on individual fibres of carbon cloth, forming a free standing positrode. Interesting SEM images of the nanotubes on single fibre are presented. CVs and GCDs were systematically applied to study the composite, revealing a positive contribution from Se doping to Nernstian storage capacity.

[39] Lin JH, Yan YT, Zheng XH, Zhong ZX, Wang YH, Qi JL, Cao J, Fei WD, Huang YD, Feng JC: Designing and constructing core-shell $\mathrm{NiCo}_{2} \mathrm{~S}_{4} @ \mathrm{Ni}_{3} \mathrm{~S}_{2}$ on Ni foam by facile one-step strategy as advanced battery-type electrodes for supercapattery. J Colloid Interface Sci 2019, 536:456-462. https://doi.org/10.1016/i.jcis.2018.10.072

[40] Lee HW, Shinde NM, Shinde PV, Yun JM, Song PK, Kim WH: High energy and power density of self-grown CuS@Cu2O core-shell supercapattery positrode. J Solid State Electrochem 2019, 23:2609-2617. https://doi.org/10.1007/s10008-019-04351-0.

[41] Punde NS, Rajpurohit AS, Srivastava AK: Fabrication of an advanced symmetric supercapattery based on nanostructured bismuth-cobalt-zinc ternary oxide anchored on silicon carbide hybrid composite electrode. Energy Technol 2019, 7:1900387. https://doi.org/10.1002/ente.201900387

[42] Priyadharsini N, Surendran S, Senthilkumar B, Vasylechko L, Selvan RK: Synthesis and electrochemical performances of $\mathrm{\gamma}-\mathrm{KCoPO}_{4}$ nanocrystals as promising electrode for aqueous supercapatteries. ChemElectroChem 2019, 6:369-377.

https://doi.org/10.1002/celc.201801440

[43] Iqbal J, Numan A, Jafer R, Bashir S, Jilani A, Mohammad S, Khalid M, Ramesh K, Ramesh $S$ : Ternary nanocomposite of cobalt oxide nanograins and silver nanoparticles grown on reduced graphene oxide conducting platform for high-performance supercapattery electrode material. J Alloys Compd 2020, 821:153425.

https://doi.org/10.1016/i.jallcom.2019.153452

[44] Raj CJ, Manikandan R, Yu KH, Nagaraju G, Park MS, Kim DW, Park SY, Kim BC:

Engineering thermally activated $\mathrm{NiMoO}_{4}$ nanoflowers and biowaste derived activated carbon-based electrodes for high-performance supercapatteries. Inorg Chem Front 2020, 7:369-384. https://doi.org/10.1039/c9qi01085h

[45]** Zhuang BY, Wu ZJ, Chu WJ, Gao YF, Cao ZZ, Bold T, Yang NJ: High-performance lithium-ion supercapatteries constructed using Li3V2(PO4)3/C mesoporous nanosheets. ChemstrySelect 2019, 4:9822-9828. https://doi.org/10.1002/slct.201902966

This is a systematic study of the interesting electrochemistry of $\mathrm{V}(\mathrm{I}, \mathrm{II}, \mathrm{III})$ in the title mentioned composite for lithium storage at high positive potentials ( 3.0 to $4.3 \mathrm{~V} \mathrm{vs}$. $\mathrm{Li}^{+} / \mathrm{Li}$ ) in mixed organic carbonate electrolyte. The specific energy of a supercapattery of the composite negatrode and an activated carbon positrode was measured to be $53 \mathrm{Wh} / \mathrm{kg}$ at a cell voltage of $2.7 \mathrm{~V}$. The mass ratio of negatrode-to-positrode was $2: 1$, but no explanation was given how this ratio was selected, implying further improvement may be achievable 
upon optimisation of the negatrode-to-positrode mass ratio, and also the cell voltage according to equations (15) and (16).

[46] Yu LP, Chen GZ: Redox electrode materials for supercapatteries, J Power Sources 2016, 326: 604-612.

http://dx.doi.org/10.1016/i.jpowsour.2016.04.095

[47] Srinivasan V, Weidner JW: Studies on the capacitance of nickel oxide films: effect of heating temperature and electrolyte concentration. J Electrochem Soc 2000, 147:880-885. https://doi.org/10.1149/1.1393286

[48] Jin XB, Zhou W, Zhang SW, Chen GZ: Nanoscale micro-electrochemical cells on carbon nanotubes. Small 2007, 3:1513-1517. https://doi.org/10.1002/smll.200700139

[49] Mane VJ, Malavekar DB, Ubale SB, Bulakhe RN, In I, Lokhande CD: Binder free lanthanum doped manganese oxide @ graphene oxide composite as high energy density electrode material for flexible symmetric solid state supercapacitor. Electrochim Acta 2020, 335:135613. https://doi.org/10.1016/i.electacta.2020.135613

[50] Hu YT, Wu Y, Wang J: High-performance energy storage: manganese-oxide-based electrode materials for energy storage applications: How close are we to the theoretical capacitance? Adv Mater 2018, https://doi.org/10.1002/adma.201870364

[51] Frackowiak E, Meller M, Menzel J, Gastol D, Fic K: Redox-active electrolyte for supercapacitor application. Farad Discuss 2014, 172: 179-198.

https://doi.org/10.1039/C4FD00052H

[52] Akinwolemiwa B, Wei CH, Yang QH, Yu LP, Xia L, Hu D, Peng C, Chen GZ: Optimal utilisation of combined double layer and Nernstian charging of activated carbon electrodes in aqueous halide supercapattery through capacitance unequalisation. $J$ Electrochem Soc 2018, 165:A4067-A4076. https://doi.org/10.1149/2.0031902jes

[53]** Abbas Q, Fitzek H, Pavlenko V, Gollas B: Towards an optimized hybrid electrochemical capacitor in iodide based aqueous redox-electrolyte: Shift of equilibrium potential by electrodes mass-balancing. Electrochim Acta 2020, 337:135785.

https://doi.org/10.1016/i.electacta.2020.135785

A very simple approach is proposed and tested successfully to avoid redox cycling of iodide and tri-iodide ions between the positrode and negatrode of the same carbon material by limiting the discharging cell voltage to $0.1 \mathrm{~V}$, instead of $0 \mathrm{~V}$. This approach should also be applicable to avoid redox cycling in other supercapatteries with capacitive electrodes and redox active electrolytes.

[54]** Yu F, Zhang CM, Wang FX, Gu YY, Zhang PP, Wacklawik ER, Du AJ, Ostrikov K, Wang $\mathrm{HX}$ : A zinc bromine "supercapattery" system combining triple functions of capacitive, pseudocapacitive and battery-type charge storage. Mater Horizon 2020, 7:495-503 https://doi.org/10.1039/c9mh01353a

The authors report an effective research effort to combine three different charge storage mechanisms into a unique aqueous supercapattery. The claimed specific energy of 270 $\mathrm{Wh} / \mathrm{kg}$ (without considering the mass of added $\mathrm{KBr}$ in the electrolyte) is amongst the top range of all reported EES devices with aqueous electrolytes. 
[55] Makino S, Shinohara Y, Ban T, Shimizu W, Takahashi K, Imanishi N, Sugimoto W: 4 V class aqueous hybrid electrochemical capacitor with battery-like capacity. RSC Adv 2012, 2:12144-12147. https://doi.org/10.1039/C2RA22265E

[56] Yu LP, Chen GZ: High energy supercapattery with an ionic liquid solution of $\mathrm{LiClO}_{4}$. Faraday Discuss. 2016, 190:231-240. https://doi.org/10.1039/c5fd00232i

[57] Fic K, Frackowiak E, Beguin F: Unusual energy enhancement in carbon-based electrochemical capacitors. J Mater Chem 2012, 22:24213-24223.

https://doi.org/10.1039/C2JM35711A

[58] Chae JH, Chen GZ: 1.9 V aqueous carbon-carbon supercapacitors with unequal electrode capacitances. Electrochim Acta 2012, 86:248-254.

https://doi.org/10.1016/j.electacta.2012.07.033

[59] Garcia G, Yentosa E, Schuhmann W: Complete prevention of dendrite formation in Zn metal anodes by means of pulsed charging protocols. ACS Appl Mater Interfaces 2017, 9:18691-18698. https://doi.org/10.1021/acsami.7b01705

[60]* Garcia G, Dieckhofer S, Schuhmann W, Yentosa E: Exceeding 6500 cycles for LiFePO ${ }_{4} / \mathrm{Li}$ metal batteries through understanding pulsed charging protocols. J Mater Chem A, 2018, 6:4746-4751. https://doi.org/10.1039/C8TA00962G

A simple but effective pulsed dis-/charging protocol is proposed and demonstrated to avoid dendritic deposition of lithium metal in LIBs, which should be equally applicable in, for example, the supercapattery of "Li | $\mathrm{LiClO}_{4}$ in ionic liquid | activated carbon"[56].

[61]* Li N, Wei WF, Xie KY, Tan JW, Zhang L, Luo XD, Yuan K, Song Q, Li HJ, Shen C, Ryan EM, Liu L, Wei GQ: Suppressing dendritic lithium formation using porous media in lithium metal-based batteries. Nano Lett 2018, 18:2067-2073.

https://doi.org/10.1021/acs.nanolett.8b00183

Effective suppression of dendritic deposition of lithium is reported on a copper plate covered with a porous membrane of submicron-wires of silicon nitride. The principle of this approach could be valid for deposition of other metals such as zinc and magnesium.

[62] Li LL, Li SY, Lu YY: Suppression of dendritic lithium growth in lithium metal-based batteries. Chem Commun 2018, 54:6648-6661. https://doi.org/10.1039/c8cc02280a

[63]* Sun S, Zhai T, Liang CL, Savilov S, Xia H: Boosted crystalline/amorphous $\mathrm{Fe}_{2} \mathrm{O}_{3-\delta}$ core/shell heterostructure for flexible solid-state pseudocapacitors in large scale. Nano Energy 2018, 45:390-397. https://doi.org/10.1016/j.nanoen.2018.01.015

Iron oxide is one of the few metal compounds that are redox active at negative potentials. Combining crystalline and amorphous iron oxide into a core/shell structure increases significantly the negatrode dis-/charging capacity in an alkaline LiOH electrolyte. The CVs and GCDs show clear supercapattery feature as represented by Fig. $2 a$ and $2 b$.

[64] Kang MX, Zhou S, Zhang J, Ning F, Ma CP, Qiu ZM: Facile fabrication of oxygen vacancyrich $\alpha-\mathrm{Fe}_{2} \mathrm{O}_{3}$ microspheres on carbon cloth as negative electrode for supercapacitors. Electrochim Acta 2020, 338:135820. https://doi.org/10.1016/j.electacta.2020.135820

[65] Huang CQ, Zhu QC, Zhang W, Qi PC, Xiao Q, Yu Y: Facile preparation of $\mathbf{W}_{5} \mathbf{O}_{14}$ nanosheet arrays with large crystal channels as high-performance negative electrode for 
supercapacitor. Electrochim Acta 2020, 330:135209.

https://doi.org/10.1016/i.electacta.2019.135209

[66] Linde E: The question of electrolytical dissociation of water in salt solutions. Zeitschrift für Elektrochemie und Angewandte Physikalische Chemie 1923, 29:163-168

[67] Dou QY, Lei SL, Wang D-W, Zhang QN, Xiao DW, Guo HW, Wang AP, Yang H, Li YL, Shi SQ, Yan XB: Safe and high-rate supercapacitors based on an "acetonitrile/water in salt" hybrid electrolyte. Energy Environ Sci 2018, 11:3212-3219.

https://doi.org/10.1039/C8EE01040D

[68] Bu XD, Su LJ, Dou QY, Lei SL, Yan XB: A low-cost "water-in-salt" electrolyte for a 2.3 V high-rate carbon-based supercapacitor. J Mater Chem A 2019, 7:7541-7547.

https://doi.org/10.1039/c9ta00154a

[69]* Ma MY, Shi ZD, Li Y, Yang YF, Zhang YX, Wu Y, Zhao H, Xie EQ: High-performance 3 V "water in salt" aqueous asymmetric supercapacitors based on VN nanowire electrodes. $J$ Mater Chem A 2020, 8:4827-4835. https://doi.org/10.1039/c9ta12709g

The authors grew nanowires of vanadium nitride on carbon cloth and coupled the composite with electro-deposited manganese oxide on carbon cloth to form an asymmetrical supercapacitor (actually a supercapattery). The materials and cell were analysed by electrochemical means in an typical "water in salt" electrolyte, i.e. $21 \mathrm{~m}$ aqueous solution lithium bis(triuoromethane sulfonyl)imide (LiTFSI) which allowed a cell voltage of $3.0 \mathrm{~V}$. Note that this work is on using, but not studying "water-in-electrolyte".

[70] Suo LM, Borodin O, Gao T, Olguin M, Ho J, Fan XL, Luo C, Wang CS, Xu K: "Water-in-salt" electrolyte enables high-voltage aqueous lithium-ion chemistries. Science 2015, 350:938943. https://doi.org/10.1126/science.aab1595

[71] Xia L, Yu LP, Hu D, Chen GZ: Electrolytes for electrochemical energy storage. Mater Chem Front 2017, 1:584-618. https://doi.org/10.1039/c6qm00169f

[72] Yu LP, Chen GZ: Ionic liquid-based electrolytes for supercapacitor and supercapattery. Front Chem 2019, 7:272. https://doi.org/10.3389/fchem.2019.00272

[73] Mishra A, Shetti NP, Basu S, Reddy KR, Aminabhavi TM: Chapter 7 - Recent developments in ionic liquid-based electrolytes for energy storage supercapacitors and rechargeable batteries, in Green Sustainable Process for Chemical and Environmental Engineering and Science--- Ionic Liquids as Green Solvents, eds. Inamuddin, Asiri AM, Kanchi S, Elsevier, 2020, 199-221. https://doi.org/10.1016/C2018-0-01748-X

[74] Shimooka T, Yamazaki S, Sugimoto T, Jyozuka T, Teraishi H, Nagao Y, Oda H, Matsuda Y, Ishikawa M: Capacitance enhancement of aqueous EDLC systems by electrochemical treatment. Electrochemistry 2007, 75:273-279. (in Japanese) https://www.jstage.jst.go.jp/article/electrochemistry/75/3/75 3 273/ pdf

[75] Han CP, Tong J, Tang X, Zhou D, Duan H, Li BH, Wang GX: Boost anion storage capacity using conductive polymer as a pseudocapative cathode for high-energy and flexible lithium ion capacitors. ACS App Mater Interfaces 2020 (online). https://doi.org/10.1021/acsami.9b22081 
[76] Zhou X, Peng C, Chen GZ: 20 V stack of aqueous supercapacitors with carbon (-), titanium bipolar plates and CNT-polypyrrole composite (+). AlChE J 2012, 58:974-983. https://doi.org/10.1002/aic.12632

[77]** Evanko B, Yoo SJ, Lipton J, Chun S-E, Moskovits M, Ji XL, Boettcher SW, Stucky GD: Stackable bipolar pouch cells with corrosion-resistant current collectors enable high-power aqueous electrochemical energy storage. Energy Environ Sci 2018, 11:2865-2875.

https://doi.org/10.1039/C8EE00546J

The work reported is a conductive and non-permeable polymer-carbon composite membrane as thin as $40 \mu \mathrm{m}$. The conductivity of the composite is actually not very high in comparison with conventional conducting materials, but because of the thinness of the membrane, the through plane resistance of the membrane is sufficiently small. The challenging task is then to make such a thin membrane non-permeable to ions in aqueous solution, which seems to be successfully achieved. The work represents an important progress in development of affordable and corrosion resistant bipolar plate materials to serially stack multiple EES cells.

[78] Hansson J, Li Q, Smith A, Zakaria I, Nilsson T, Nylander A, Ye LL, Lundgren P, Liu J, Enoksson P: Bipolar electrochemical capacitors using double-sided carbon nanotubes on graphite electrodes. J Power Sources 2020, 451:227765.

https://doi.org/10.1016/i.jpowsour.2020.227765

9. Figures and captions
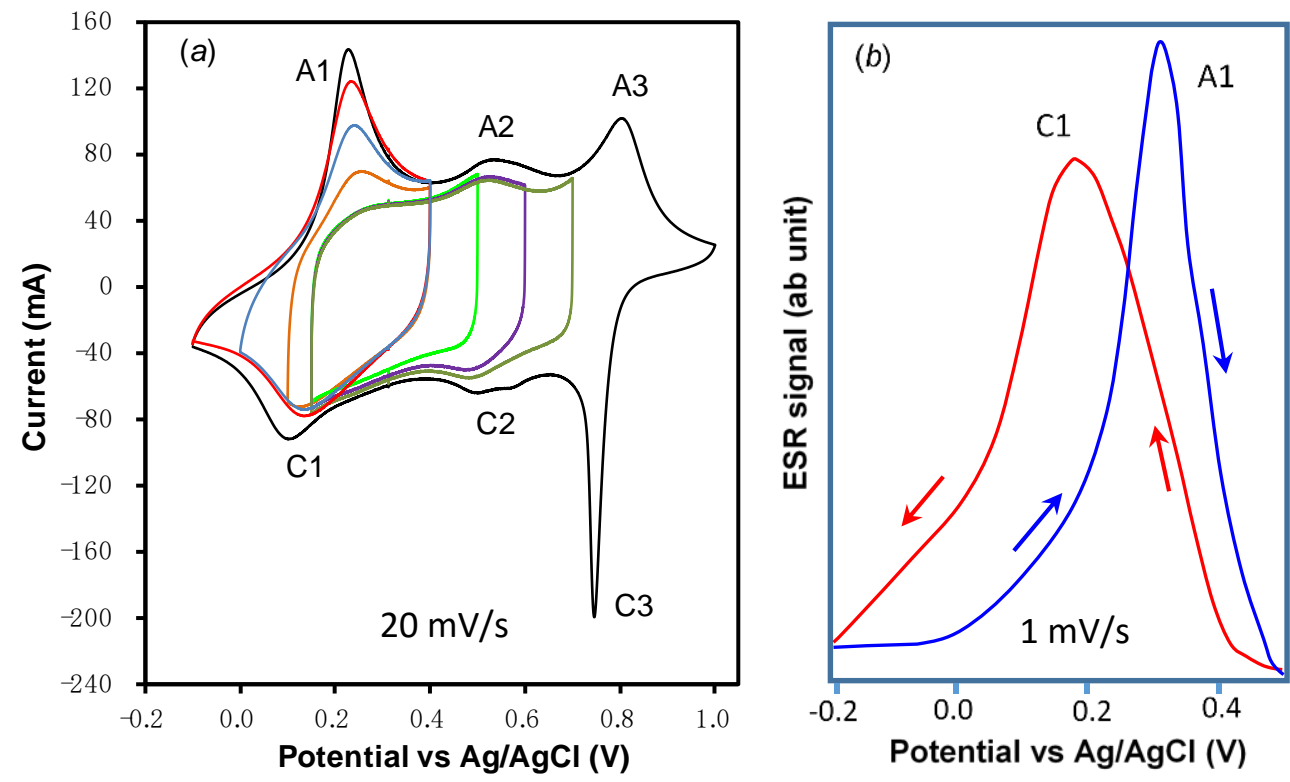

Fig. 1. (a) CVs in different potential ranges, and (b) a cyclic esrogram of electrodeposited polyaniline in acidic aqueous electrolytes. Redrawn from refs [34] and [30]. 

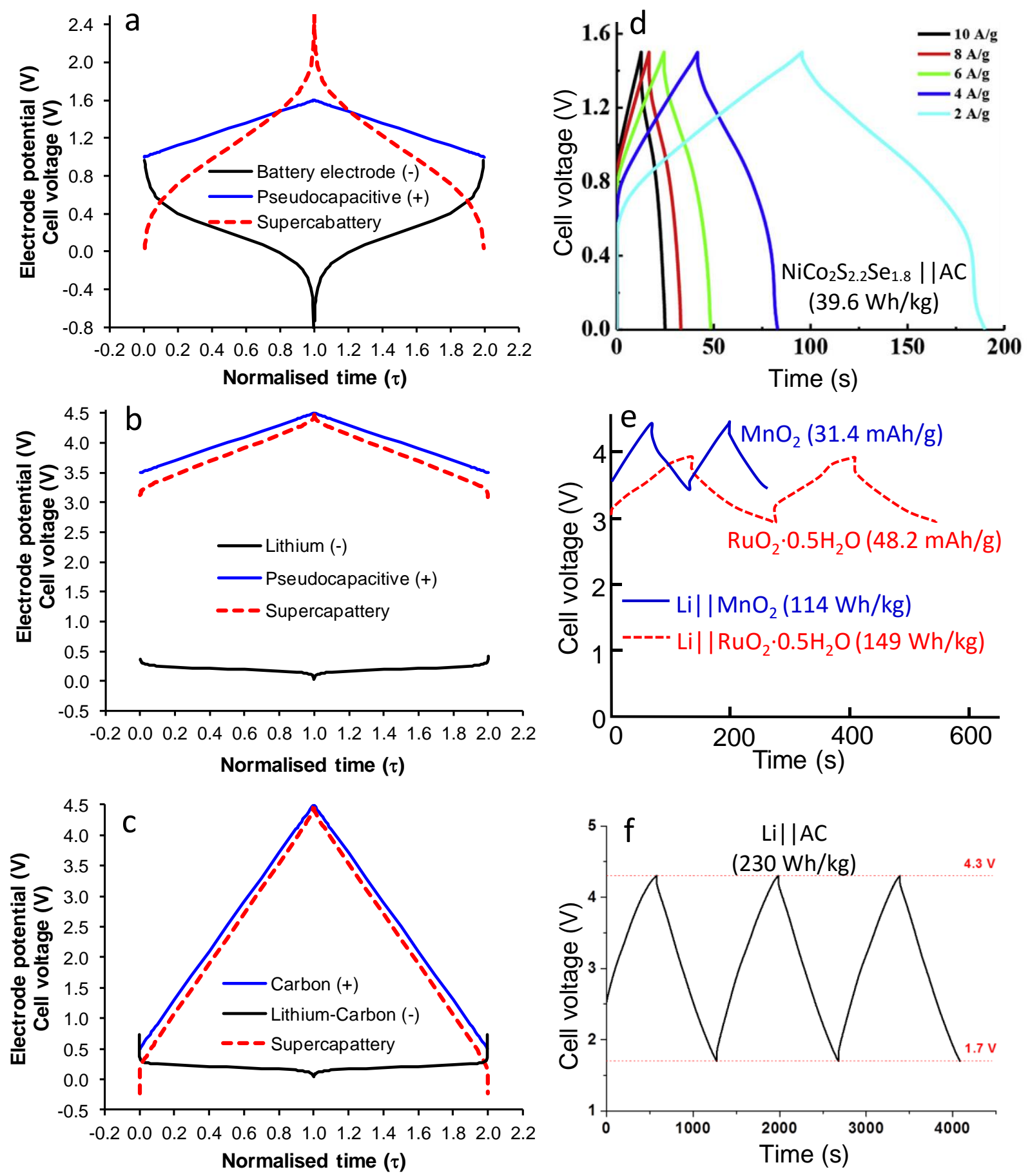

Fig. 2. (a-c) Calculated GCD plots of potentials of the positrode (blue line) and negatrode (black line), and the cell voltage (red dashed lines) as a function of normalised time for three supercapatteries combining a pseudocapacitive positrode of narrow potential window with a Nernstian negatrode of quasi-reversibility (a), and a lithium metal or lithiated carbon negatrode (b), and an activated carbon positrode of wide potential window, and a lithiated carbon negatrode (c). (d-f) Experimentally recorded GCD plots of the cell voltage against time for supercapatteries with aqueous (d), ionic liquid (e), and aqueous + solid electrolytes. Redrawn from $[4,38,55,56]$. 

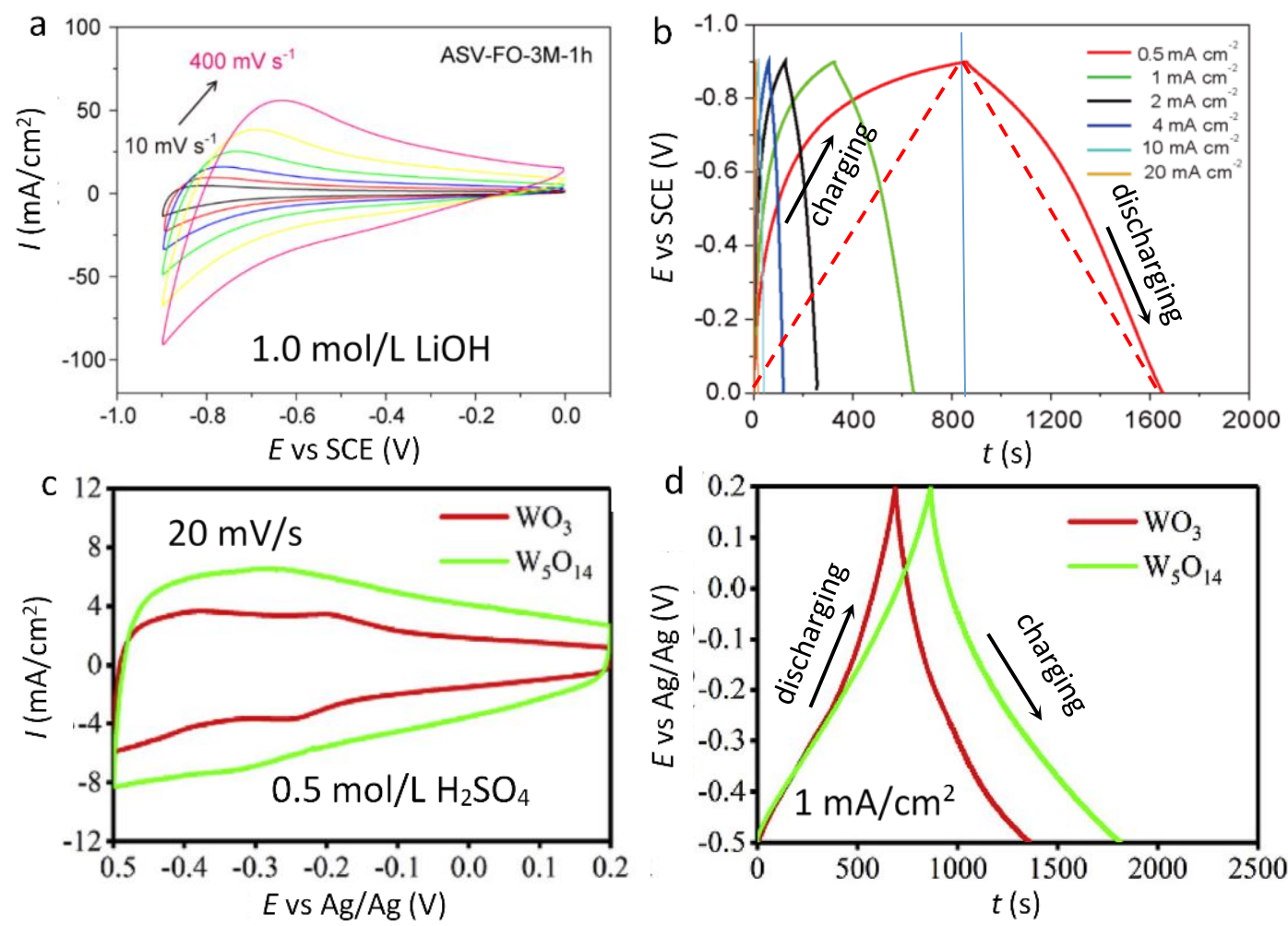

Fig. 3. $(a, c) C V s$ and $(b, d) G C D s$ of nanostructured and oxygen deficient $(a, b)$ iron oxide, and $(c, d)$ tungsten oxides. Redrawn from refs. $[63,65]$. 

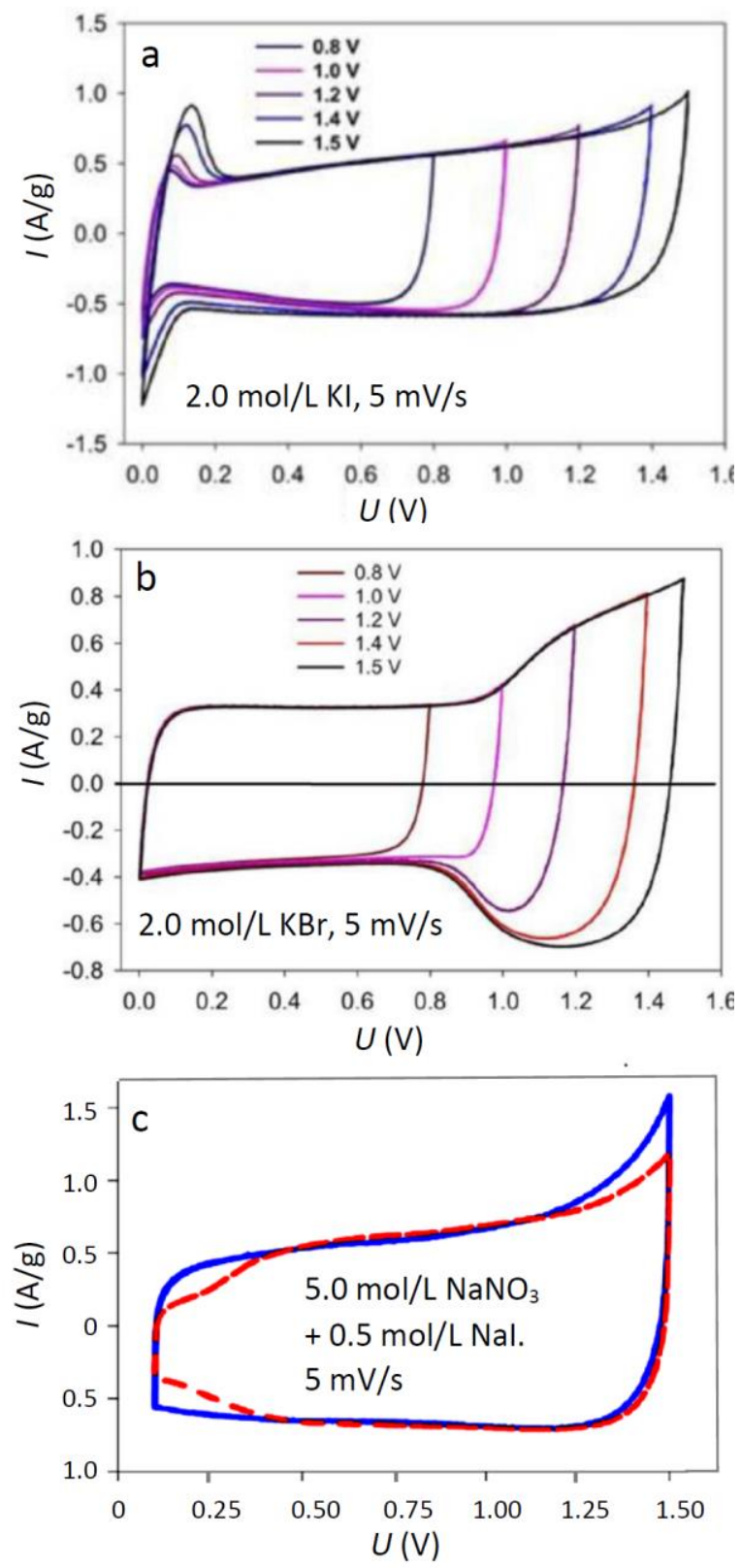

Fig. 4. CVs of supercapattery with activated carbon positrode and negatrode containing indicated electrolytes. Note that the potential window is from 0 to 1.5 $\mathrm{V}$ in (a) and (b) but from 0.1 to $1.5 \mathrm{~V}$ in (c) where the black line and red dashed line CVs were recorded before and after 100 charging-discharging cycles. Redrawn from refs. [52, 53] 